\title{
Análisis de En la ciudad (2003) de Ces Gay como modelo de autor en el cine español contemporáneo
}

\author{
Analysis of In the city (2003) by Cesc Gay as an author model in \\ contemporary Spanish cinema
}

\author{
Ernesto Taborda-Hernandez \\ Universidad Rey Juan Carlos \\ ernesto.taborda@urjc.es \\ Francisco Javier Miranda García \\ Universidad Rey Juan Carlos \\ javier.miranda@urjc.es
}

\section{Resumen:}

El cine español tiene muchas virtudes: industrial, bien cultural y como tradición arraigada a lo largo de los años; ha cosechado éxitos y profundos aportes al medio cinematográfico que sus directores y sus películas han hecho. Otra de las virtudes es que, en las pasadas décadas, de finales y de comienzos de siglo, siempre ha predominado la elección del factor personal como criterio de referencia en la elaboración de las películas. La mayoría de sus directores se convierten en autores desde esa personalidad artística única, que hace diferenciar sus películas de entre muchas por la temática, el lenguaje y la manera de afrontar las historias. En este contexto, el cine de Cesc Gay, especialmente su segunda película, En la ciudad (2003), sirve como guía para analizar al director como modelo de autor de ese cine español de entre milenios, desde el uso del lenguaje, las herramientas narrativas y los recursos expresivos, utilizando un modelo de análisis que permita obtener elementos afines y diferenciales, tanto en su obra como en la obra de otros autores, de manera que se pueda ampliar este acercamiento a otras películas y directores españoles y europeos.

\begin{abstract}
:
The Spanish cinema has many virtues, as an industry, as a cultural asset and as a tradition rooted over the years, of the successes and of the profound contributions to the cinematographic medium that its directors and their films have made. One of these virtues is that in the past decades, the end and the beginning of the century, the choice of the personal factor has always predominated as a reference criterion in the making of films. Its directors, for the most part, become authors from that unique artistic personality, which differentiates their films from among many due to the theme, language and way of dealing with stories. In this context, Cesc Gay's cinema, especially his second film, En la ciudad (2003), serves as a guide to analyze the director as an author model of that Spanish cinema between millennia, from the use of language, narrative tools and expressive resources, using an analysis model that allows obtaining related and differential elements, both in his work and in the work of other authors, so that this approach can be extended to other Spanish and European films and directors.
\end{abstract}

Palabras clave: Cine español; Análisis cinematográfico; Modelo de autor; Ces Gay; En la ciudad.

Keywords: Spanish cinema; Film analysis; Author`s model; Cesc Gay; En la ciudad. 


\section{El cine español del S. XXI}

La última década del siglo pasado fue satisfactoria para el cine español. Dos premios Oscar de la academia de USA: uno para Fernando Trueba por Belle Époque (1994) y el otro para Pedro Almodóvar por Todo sobre mi madre (1999). Según el informe del ICAA (2020), se realizaron 840 películas, de las cuales 225 correspondían a directores noveles. Dichos datos en sí mismos no aportan otros datos relevantes. De la cantidad señalada, ¿cuántos directores han logrado producir su segunda película? ¿Cuánto obtuvieron de beneficios en taquilla?

En el año 2000, los espectadores nacionales acudieron al cine más veces que la media europea, pero sería interesante confrontar estos datos respecto a las películas no europeas o latinoamericana? Al año siguiente, el número de espectadores aumentó considerablemente, de 13,4 a 26,2 millones. Ese año se estrena Torrente 2: Misión en Marbella (Santiago Segura, 2001), que obtiene 5,3 millones de espectadores, poco más del $5 \%$ de la cuota de pantalla, siendo la total un $17,8 \%$, la más alta de la primera década del siglo según los informes que ofrece el MECD (2011).

Entre 2001 y 2010, se produjeron 1469 películas españolas y en coproducción. En 2018 y 2019 hicieron unas cifras de recaudación similares, 214 largometrajes íntegramente nacionales con 52 coproducciones en 2018, y 51 en 2019. (Anuario de cine, ICAA). Todos estos números y películas mantienen claramente una industria con bastante solidez, pero, si la mayoría de ellas no funcionan económicamente en la taquilla, la situación es muy preocupante.

El promedio de espectadores de la década fue de 14,8\%, en un mercado de 500 a casi 700 millones de euros anuales. En el 2010 se recaudaron 80,28 millones, mientras que las películas extranjeras recaudaron 582,03 millones. Eso significa que como industria no se tiene la capacidad de hacer más que un $13 \%$, casi $14 \%$, de la recaudación total.

Es inquietante pensar en algunas situaciones y analizar determinadas películas para encontrar explicaciones a los acontecimientos. En 2014, Carlos Vermut estrena su segundo largometraje, titulado Magical Girl (2014), con un 
presupuesto de 500 mil euros. Obtiene la Concha de Oro a mejor película y la Concha de Plata al mejor director en el Festival de San Sebastián, nominada a 7 Goyas, obteniendo el de mejor actriz para Bárbara Lennie. El largometraje recaudó en España 256 mil euros con 53492 espectadores, un dato curioso es que Francia durante su primera semana había recaudado 111 mil euros con 22674 espectadores (Partearroyo, 2015). Luego en 2018, Vermut, estrena Quien te cantará (2018) con presupuesto de 2,5 millones y una muy pobre recaudación en España, de poco más de 175 mil euros. Película peculiar como la filmografía del director que cuenta con un casting muy potente: Najwa Nimri, Natalia de Molina (2 Goyas) y la mejor actriz de reparto de esa edición de los Goya, Eva Llorach. La película tenía buenos elementos para que con una buena campaña de marketing se pudiera atraer al público para incitarlo a ir a las salas comerciales a consumir el producto; solo imaginarse una valla en la Plaza de Callao con el cartel con la fotografía de Nimri y Llorach con ese corte de pelo tan llamativo seguro que hubiese ayudado.

El cine español es una de las cinematografías que tiene más marcas claras de autoría con un sello diferenciador, que podríamos llamar cine marca España y que podría ser perfectamente reconocible por todo el mundo. Los temas que trata son de actualidad y conectan con la realidad, dejando a un lado algunas películas que toman modelos que no son propios de nuestra realidad, como son películas genéricas inspiradas en modelos muy taquilleros del cine norteamericano, que también son viables y que tienen cabida en esta cinematografía, pero que hay que saber enfocar.

Se ha intentado definir el cine español intentando identificar su tipología y tendencias más frecuentes. Faulkner \& Cuesta (2017) manifiestan su complejidad y comentan que después de que, según muchos expertos, a principios de los 90 estaban en muy mala situación, poco después repuntara con un grueso de películas de directores personales autores, con además buena repercusión en taquilla. También en qué medida el cine español de la década de los noventa respondía a ciertos criterios claves en lo que a un nuevo concepto de autor o de cine de autor contemporáneo. En su mayoría, el cine español de la década está formado por directores que manejan un lenguaje propio que utilizan recursos 
narrativos muy específicos y cómo estos recursos ayudan a que su cine sea reconocible (Taborda-Hernández, 2014). Para muchos autores el cine español es un cine personal (Heredero \& Santamaría, 2002) y que por su carácter de “autor” debía ser salvaguardado y protegido para promover esta tendencia en la producción y por su alto nivel de calidad, además de ser un bien cultural, debería ser protegido para asegurar un buen desempeño económico.

\subsection{Los directores y sus películas en cifras}

A día de hoy, la cuota de mercado del cine nacional no está al alza, pero si se observan los estrenos desde 1990 hasta 2019 se puede concluir que a lo largo de dos décadas si hubo un incremento de distribución en lo que a cine español se refiere, ya que se pasó de 47 a 207 estrenos. El año con menor logro de proyecciones fue 1994 con un 7,1\% y el de mayor exhibición fue el 2001 con un $17,81 \%$.

Al mirar las películas que más recaudaron en el año 2001 sorprende que Los Otros (Amenábar, 2001) haya sido la más taquillera, por encima de Torrente 2 (Segura, 2001). Por su parte, es esperanzador que directores como Vicente Aranda y Julio Medem gracias a sus respectivos largometrajes como Juana La Loca (Aranda, 2001) y Lucía y el sexo (Medem, 2001) estén posicionados en la tercera y cuarta película con mayor recaudación del año citado. Exceptuando el caso de Santiago Segura y su trayectoria en los últimos años, los otros tres directores son considerados autores. Las referencias de Amenábar en Los Otros vienen del cine de suspense y los recursos que emplea muestran a un autor con referencias claras y recursos expresivos recurrentes. Vicente Aranda fue probablemente el director español más autor durante toda su extensa y compacta cinematografía. El cineasta barcelonés ha conseguido estrenar 25 películas a lo largo de su trayectoria cinematográfica. Si observamos su filmografía detalladamente un tema que ha mostrado de manera asidua ha sido el amor loco, pero ha sabido patentarlo con gran profundidad y sin caer en lo reiterativo, algo que nos permite enmarcarlo como un claro autor por la forma en la que se nos presenta este tipo de argumento. El universo onírico, el peso del pasado y la casualidad tan presentes en el cine de Julio Medem hacen que Lucía y el sexo sea 
la obra de un autor ya consagrado con unas profundas marcas recurrentes y notables en todas sus películas, incluyendo las fallidas o desacertadas.

Por otra parte, si se observan los grandes éxitos de público y taquilla dentro del cine español desde 1990 hasta 2010 podemos darnos cuenta de que son películas de directores con sello personal, de autor. Los datos nos deben invitar a reflexionar sobre el tipo de cine que se debe fomentar, la posible tendencia comercial y qué tipo de cine debería ser la piedra angular de la industria. (Anuario del cine. ICAA. 1990-2010).

Con la llegada del nuevo milenio la película más taquillera fue La Comunidad (De la Iglesia, 2000) con 1.382.216 espectadores (ICAA, 2000), el año anterior fue Todo sobre mi madre (Almodóvar, 1999), película que figura en el puesto 8 como una de las más taquilleras de todos los tiempos (2021) a nivel mundial. En 1998, las más taquilleras son Torrente, el brazo tonto de la ley (Segura), Abre los ojos (Amenábar), La Niña de tus ojos. (Trueba), Cha-cha-cha (Del Real), Los amantes del círculo polar (Medem) y Barrio (León de Aranoa). Dentro del listado nombrado, podríamos desglosar del cine de autor la primera y la cuarta película, pero si lo comparamos con fórmulas de otros países, sí que podríamos etiquetarlas como cine de marca española. El resto de los largometrajes son de autor indiscutiblemente.

Amanece que no es poco (Cuerda, 1993), Mar Adentro (Amenábar, 2004), Volver (Almodóvar, 2006) son películas que aparecen como la segunda mejor posicionada de sus años (las tres son como mejor posicionadas). En tercer lugar, de su año están Libertarias y Carmen (Aranda, 1996, 2003), Princesas (León de Aranoa, 2005) y Celda 211 (Monzón, 2009), todos directores que según muchos teóricos (Riambau, 1994, Heredero, 2002, etc.) son considerados autores, que hacen cine personal, etc.

El cine español se construye bajo una identidad nacional muy clara que incluso dentro de géneros muy enmarcados y representativos, conforman una identidad única que hacen una marca clara en sus películas y en sus directores. 


\section{El paradigma del cine de autor}

En Francia, a finales de los años 50 se forja el movimiento artístico más influyente de la historia del cine, lo que hoy se conoce como la Nouvelle Vague. Fue una generación de cineastas que querían mostrar su propio sello, no solo en la forma de narrar sino en la manera de filmar y montar las películas. Muchos de los directores fueron críticos de la revista Cahiers du cinema, que dirigía André Bazin, quien en 1958 publica el libro Qu'est-ce que le cinema (1958-1963), obra emblema del movimiento y uno de los grandes textos de teoría del cine.

Los 400 Golpes (Les Quatre Cents Coups, François Truffaut, 1959), Al final de la Escapada (À bout de souffle, Jean Luc Godard,1960) son dos de las mejores muestras de las teorías de Bazin. Precisamente Truffeau proclamó que autor es aquél que dirige la película independientemente de que no haya escrito ninguna línea del guion, dirigido a actores ni escogido el ángulo de la cámara porque "una película siempre refleja a quien firma su realización” (Truffaut, 2002, p. 15 en Malpartida Tirado, 2012, p. 12).

¿Qué fue la Nouvelle Vague como movimiento sino una reivindicación del autor y de su discurso personal y único? (Moncasí, 2018). Cabe matizar que lo que históricamente se conoce como cine de autor hace referencia al movimiento francés y se debe diferenciar de lo que podemos llamar directores con sello propio, que alejados de la nouvelle vague o en la misma línea, presentan unos elementos diferenciadores en cuanto a historias, lenguaje, recursos y estética.

No se puede tampoco olvidar que la forma de hacer cine de autor ha cambiado con los años. Desde que finalizó la Segunda Guerra Mundial hasta la década de los 8o, el cine contaba con una perspectiva social, estética y política que se englobaba dentro del marco moderno. En este entorno, el ser humano se preocupaba por la lógica y la razón como herramientas para entender el mundo y la autonomía y la voluntad son dos aspectos clave (Gutiérrez Correa, 2014, p. 3). El estreno en 1941 de Ciudadano Kane (Orson Welles) en Estados Unidos y en 1960 de $A$ bout the souffle (Jean-Luc Godard) en Francia marcan los cambios en la forma de hacer cine (Barberá, 2008, p. 83). 
Goytisolo (2017) se pregunta ¿cómo se puede comparar el actual panorama cinematográfico con el que reinaba durante la segunda mitad de siglo? ¿Qué hay ahora de comparable con las películas de directores como Bergman, con la Nouvelle Vague, con el cine italiano de un Fellini, un Visconti, un Rossellini, o con las grandes obras del cine americano? (Goytisolo, 2017, p. 78). Probablemente no hay punto de comparación, o sencillamente sea diferente.

Los parámetros para analizar el fenómeno del autor han cambiado. Ya no se enmarcan en un movimiento, aunque sí coinciden en la voluntad de expresarse a través del lenguaje y de los temas que abordan en sus películas.

\subsection{El Cine de Autor en el panorama nacional}

Si algo caracteriza al cine de autor de nuestro país en la primera década del siglo XXI es que ha apostado por el cine social como respuesta al neoliberalismo, el desmoronamiento de la sociedad del bienestar y la crisis del sistema económico (Barberá, 2008, p. 83). En concreto, el cine español de los 90 y la primera década del siglo XXI ha buscado realismo y ha abordado los problemas investigando sus causas, pero sin cubrir sus síntomas (Quintana, 2008, p. 252).

Como consecuencia de los movimientos antes citados, en los años sesenta surge en Barcelona un pequeño pero influyente movimiento llamado la Gauche Divine (Riambau \& Torreiro, 1995) que, siguiendo la vertiente cinematográfica gala, querían hacer frente al cine que los espectadores estaban acostumbrados a consumir. Directores como Vicente Aranda, Jorge Grau, José María Nunes, Jaime Camino, Jacinto Esteva o Joaquím Jordá, están relacionados con el movimiento. Paralelamente florece el llamado nuevo cine español. Se trata de un grupo de cineastas que se caracterizaban por haber sido formados en la escuela de cine y por tener ideologías contrarias al régimen. Películas como $E l$ Buen Amor (Francisco Regueiro, 1963), Young Sánchez (Mario Camus, 1964) o La Caza (Carlos Saura, 1965), son otros claros ejemplos de historias poco convencionales a las que los espectadores estaban muy poco acostumbrados, pero que a su vez se han convertido en clásicos de nuestro cine. 
Con la llegada de la democracia y la evolución natural del medio, en los 90 predomina en España un cine de autor, pero no como movimiento, como afirma Riambau (1996), sino enfocado en los directores y su reconocimiento, y donde la visión personal de cada uno resalta sobre todo lo demás.

Sobresalen marcas de autoría más por el estilo, y este se caracteriza por estar vinculado a la naturaleza del cineasta que nos mostrará gracias al lenguaje, estética y otros elementos que emplee para expresarse. Al final, en el marco de esta investigación, un autor es aquel que es capaz de elegir el factor personal como criterio de referencia y organizarlo en un modelo propio y único reconocible por todos. Siguiendo esta línea, se plantea en este estudio mostrar los aspectos que reflejan la capacidad de autor y de expresión personal como sello y marca reconocible en el realizador, en este caso en el cine del director catalán.

\section{El cine de Cesc Gay como modelo. Metodología de análisis}

El análisis audiovisual debe ser útil y estar al servicio del aporte que la obra en sí puede generar como ayuda al debate y a la ciencia. Para poder mostrar los aspectos que reflejan la capacidad de autor y de expresión personal como sello y marca reconocible, creemos oportuno centrarnos en el plano de expresión discursivo del director; en los recursos expresivos y el uso del lenguaje, sin olvidar elementos de la historia que puedan aportar aspectos a resaltar en la película.

Se han detectado los siguientes elementos más representativos y usados como variables en el análisis en la película, ya que están muy presentes en toda la cinta:

\begin{tabular}{|c|c|}
\hline Recursos Expresivos \\
\hline - & Acentuación dramática: Recurso expresivo usado para subrayar \\
& aspectos dramáticos de la historia mezclado con elementos del lenguaje. \\
\hline & Elipsis \\
\hline & Planos recurrentes \\
\hline & Transiciones \\
\hline Elementos del lenguaje \\
\hline - & Movimientos de cámara \\
\hline - & Inserto \\
\hline & Foco selectivo \\
\hline
\end{tabular}

F1. Variables de análisis. Recursos propios. 
La trayectoria de Francesc Gay i Puig se ha ido desarrollando con los años hasta consolidar una filmografía corta (8 largometrajes de ficción) pero muy enérgica y sólida, que lo llevó en 2016 a obtener en la trigésima edición de los premios Goyas cinco de los galardones más importantes con Truman (2015): Mejor Director, mejor película, mejor guion junto a su colaborador habitual Tomás Aragay, mejor actor protagonista para Ricardo Darín y mejor actor de reparto para Javier Cámara. Estos reconocimientos consuman a un director que es premio catalán de cine y que ya con su segunda película En la ciudad (2003) consiguió nominaciones importantes a los Goyas y un premio al mejor actor de reparto para Eduard Fernández.

Esta película la vieron 108.830 espectadores y obtuvo 618.800 euros de taquilla según informe ICAA (2016), aunque según otro informe actualizado en 2020 afirma que con 634.641 espectadores ha recaudado 3.589.119,96 euros (ICAA, catálogo) siendo uno de los largometrajes más taquilleras del año. En Internet movie data base (IMDB) informa que tiene un acumulado mundial de 9.027.600 dólares de recaudación.

La ópera prima de Gay fue Krámpack (2000), adaptación de una obra de teatro por encargo, donde ya mostraba elementos novedosos que con el paso de las películas ha ido perfeccionando y profundizando en la sencillez del discurso, en la profundidad del relato y de la construcción del personaje basado, sobre todo, en lo que dejan de decir pero que sí se intuye y refleja en las acciones.

En la ciudad (2003) es una película coral sobre las relaciones entre un grupo de amigos, los problemas de comunicación y la ocultación de los sentimientos reales que de repente afloran en el final de la historia. Estructura muy común en su cine, que imita en Una pistola en cada mano (2012), en este caso entre hombres cuarentones en crisis con un final similar donde son superados por mujeres más centradas y sabias.

Asimismo, Truman (2015) maneja un alto grado de sensatez y ética en la manera cómo afrontan los personajes la muerte. La capacidad del director para manejar los sentimientos en sus personajes sin mostrarlos no está al alcance de muchos a nivel de lenguaje y de recursos expresivos. Requiere mucho oficio tanto a nivel 
de contenido como de discurso; cómo resuelven sus diferencias Nico y Dani en Krampack (2000), cómo los personajes de En la Ciudad (2003) admitían sus derrotas y problemas, cómo el grupo de hombres de Una pistola en cada mano (2012) encajaban la debacle generacional y la pérdida de control, o como dos amigos muestran el más profundo amor fraternal a través de un perro.

\subsection{En la ciudad (2003) y otras historias}

En la ciudad (2003) es una película coral que cuenta las relaciones de un grupo de seis amigos, de los cuales 4 son pareja. Las tramas están organizadas por los personajes y sus conflictos relacionales. Irene, Mónica López, es el hilo conductor del relato, este personaje es el que tiene mayor importancia debido al conflicto en el que se ve envuelto y a que tiene mayor peso temporal y dramático a lo largo de la película, con un total de 38:39 minutos (35,38\%) de todo el metraje. Su conflicto es de identidad, no sabe si quiere seguir con su marido, Manu, o quiere estar soltera y tener aventuras con otras mujeres. Su confrontación es tal que aborta sin comentarlo con nadie de su ambiente. Tiene una aventura con una fotógrafa que incrementa su angustia existencial. En segundo lugar, está Mario que descubre que Sara su esposa le es infiel con un compañero de la obra de teatro en la que participa y no dice nada al respecto, ni a ella ni a ningún amigo, solo casi al final, a la o1h:22minh, cuando está cenando en un restaurante por su cumpleaños y el antiguo amante de Sara llega de improvisto. Mario se enfada y les reprocha que no hacía falta que se acercara, que con un simple gesto bastaba. Ocupa 36:15 minutos (33,38\%).

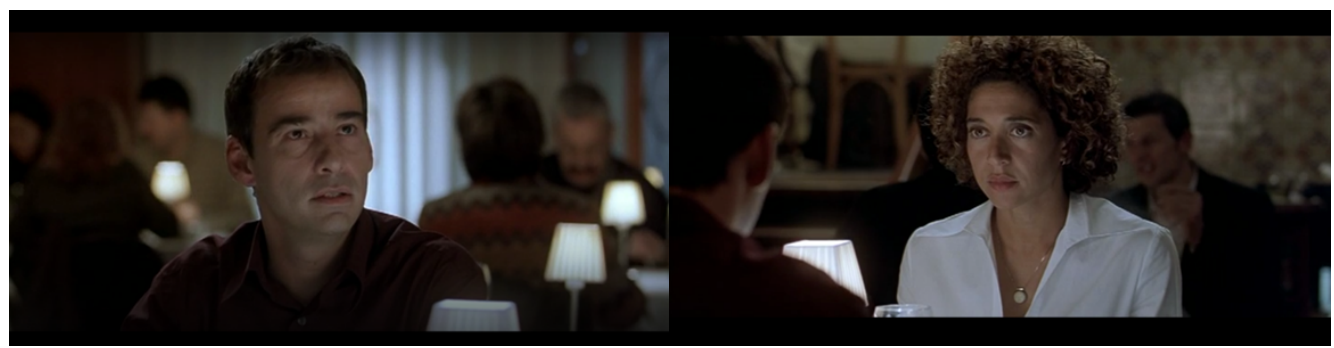

F2. En la ciudad (2003) Cesc Gay. CT 01:22:17. Captura de pantalla. https://youtu.be/N-ZJ9oExO7k

Luego está Sofía, con 33:22 (30,55\%), que se autoengaña a sí misma y a sus amigos inventándose relaciones que sí llega a tener, pero que exagera. Es una 
mitómana sin remedio que termina haciendo daño a los que están alrededor. Luego los acompañan como parejas, Manu (15,33\%) compañero de Irene sin trama propia, Sara (26,30\%), pareja de Mario con una subtrama que está relacionada con él, y por último, Tomás $(18,27 \%)$ que es un profesor de música de instituto y que tiene una relación con una de sus alumnas de 16 años que a su vez es sobrina de Mario. Tiene una trama pequeñita que comienza con la película y que termina cuando va a la comida final con la niña para que todos se enteren.

A nivel de estructura, de personajes y de estilo, esta obra tiene mucha similitud con Una pistola en cada mano (2012), al igual que en los recursos expresivos y los elementos del lenguaje, ambas mantienen mucha relación. Con la diferencia que la segunda es coral episódica y En la ciudad es coral de relaciones. Los dos largometrajes conservan el mismo sentido cuando al final de Una pistola en cada mano se establecen las relaciones estrechas entre los personajes, la dinámica de la incomunicación y los secretos.

Toda la obra de Gay tiene estos tintes y matices en mayor o menor medida. Tal vez Krámpack (2000) al ser un drama juvenil no refleje de manera tan clara estos problemas de comunicación, pero en el fondo son problemas de juventud en una etapa donde todavía no sabemos expresarnos. Truman (2015) mantiene la dinámica de diálogo entre dos personas tan presente en las anteriores con unos recursos estilísticos muy marcados a nivel de lenguaje. Su última entrega, Sentimental (2020), recuerda a la relación entre los dos amigos y las dos parejas en el episodio final de Una pistola en cada mano.

\section{Resultados}

De la combinación de recursos y elementos detectados en el análisis de la película, hay un recurso expresivo muy característico, que el director emplea en momentos determinados de la historia cuando quiere subrayar algún aspecto que puede coincidir o no con algunas de las peripecias estructurales. A ese recurso de recalcar una acción para hacerla sobresalir lo hemos llamado acentuación dramática, que combina con elementos del lenguaje como los movimientos de 
cámara que son muy particulares en sus películas. El recurso expresivo de acentuación dramática ocupa el 7,43\% de todo el metraje y aparece en 11 ocasiones. Está mezclado con elementos del lenguaje con movimientos de cámara que en total son $26,27 \%$ y que aparece 30 veces en todo el metraje.

Dicha composición le otorga una riqueza que tiene como característica principal la sutileza de la puesta en escena, junto con los movimientos de cámara muy lentos que muchas veces no se notan porque la puesta en escena está al servicio del contenido de la historia y lo que hace es acentuar los elementos importantes para el discurso.

La trama de Irene es la más importante y que conjunta todas las demás. Después de las presentaciones de cada personaje, Irene, Sara y Sofía van a comer juntas. Irene ve a lo lejos a una antigua amante, de esas relaciones homosexuales que ha mantenido ocultas al margen de su relación con Manu. Esta relación será junto con su embarazo inesperado lo que motive la decisión que pretende tomar al final de la película, pero se lo impiden inconscientemente Manu, y su grupo de amigos. El conflicto de Irene es de identidad y en la comida se presenta un plano fijo perfectamente equilibrado de las tres amigas hablando, Irene está en el centro de la imagen, la conversación entre Sofía y Sara es indiferente. Sara va al baño y Sofía recibe una llamada de teléfono y también se ausenta, decide dejar el plano

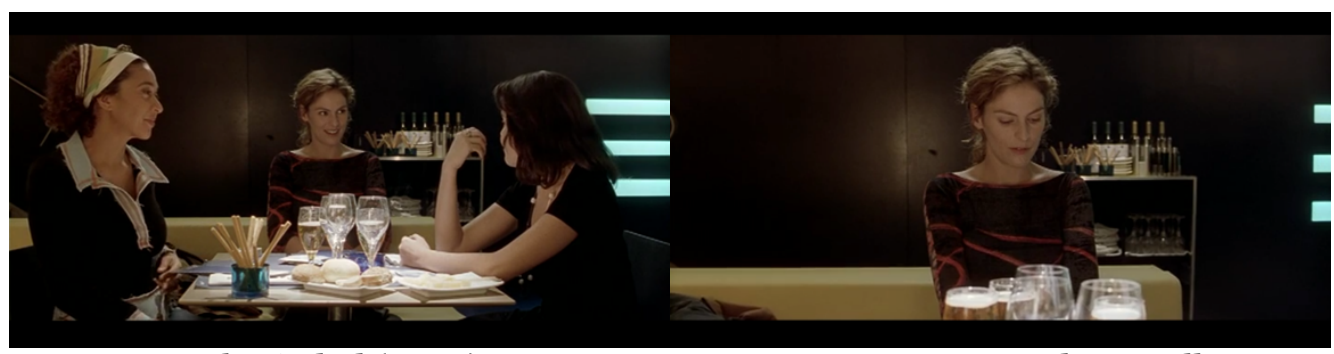

F3. En la ciudad (2003) Cesc Gay. CT oo:07:14.937. Captura de pantalla. https://youtu.be/MGovWLx3X_4

fijo para clavar la atención en Irene y la fotógrafa que llegará. Hace un travelling hacia adentro para remarcar la acentuación dramática del sentimiento de Irene (oo:07:14.937). Incluye un inserto de plano subjetivo de Irene que mira a la fotógrafa que llega en ese instante. Será más adelante la acción detonante de la decisión que toma Irene al final de la película. Sofía y Sara vuelven y ofrece el clásico plano contra plano con referencia del otro personaje (oo:07:44.865) 
intercalado con plano de conjunto de las tres, mientras Sofía cuenta su historia con Eric que después se verá que es una mentira.

Asimismo, Sofía que es el tercer personaje en orden de aparición, también guarda muchos secretos, menos importantes que los de Irene, pero igual de tóxicos. Ella es mitómana y en la secuencia anterior ya nos han ofrecido algunos indicios de su condición psicológica. En el oo:28:56.854, en una acción sencilla casi imperceptible cuando en su casa suena el teléfono, ella se levanta y va al baño. La cámara se mantiene a la altura de sus ojos, de cuando estaba sentada, en el mismo lugar, pero comienza a moverse lentamente hasta llegar a un primer plano de ella, que cuando regresa se vuelve a sentar. Es un recurso expresivo muy complejo de acentuación dramática porque nos está contando definitivamente que Sofía es una mitómana, por la manera como le miente a su amigo Tomás para no salir con él. Al igual que en el o0:34:04.810 cuando Sofía entra en una agencia de viajes a preguntar cuánto cuesta un boleto a París y se lleva un folleto de las Canarias. Se muestra con un movimiento de cámara que va de la ventana del local hasta la puerta desde dentro, una vez que ella se sienta la cámara corrige y reencuadra. La secuencia está construida como una descripción más, aunque es un recurso expresivo que luego tendrá más valor. Por último, con la aparición de Eric nuevamente después de varios meses, Sofía ha establecido una relación con Andrés, al que deja plantado sin razón. Antes, en el 01:05:41.36, hay otro elemento del lenguaje poco utilizado pero muy oportuno que es el foco selectivo, este aparece dos veces y ocupa el o,34\% de la película y precisamente con Sofía. Eric ve a Sofía comiendo y se acerca a saludarla. Hay un cambio de foco entre él y ella, y de vuelta a Sofía. Él le cuenta que ha llegado hace dos días y que está buscando piso. Luego, Sofía escucha un mensaje en el contestador (01:09:27.43); es de Andrés que le cuenta que ha quedado con su hermano en casa esa noche. Con la llegada de Eric, Sofía está actuando de manera extraña, hay un plano que lo refleja de manera muy expresiva. Desde el inodoro hay un travelling mientras Sofía sale de cuadro hasta que entra de nuevo con una tarjeta y el teléfono marcando un número. Se entiende que es a Eric a quien llama. 
Al día siguiente (01:18:05.89), Sofía le dice a Andrés que no está enamorada de él y que ha estado con Eric. Su comportamiento es enfermizo. Andrés aguanta el golpe como puede. El director lo muestra con un plano medio fijo de Sofía y se escucha a Andrés a un lado. Poco a poco se va abriendo el plano hasta que se ve a Andrés. Sofía termina la frase pidiendo el postre porque tiene que volver al trabajo.

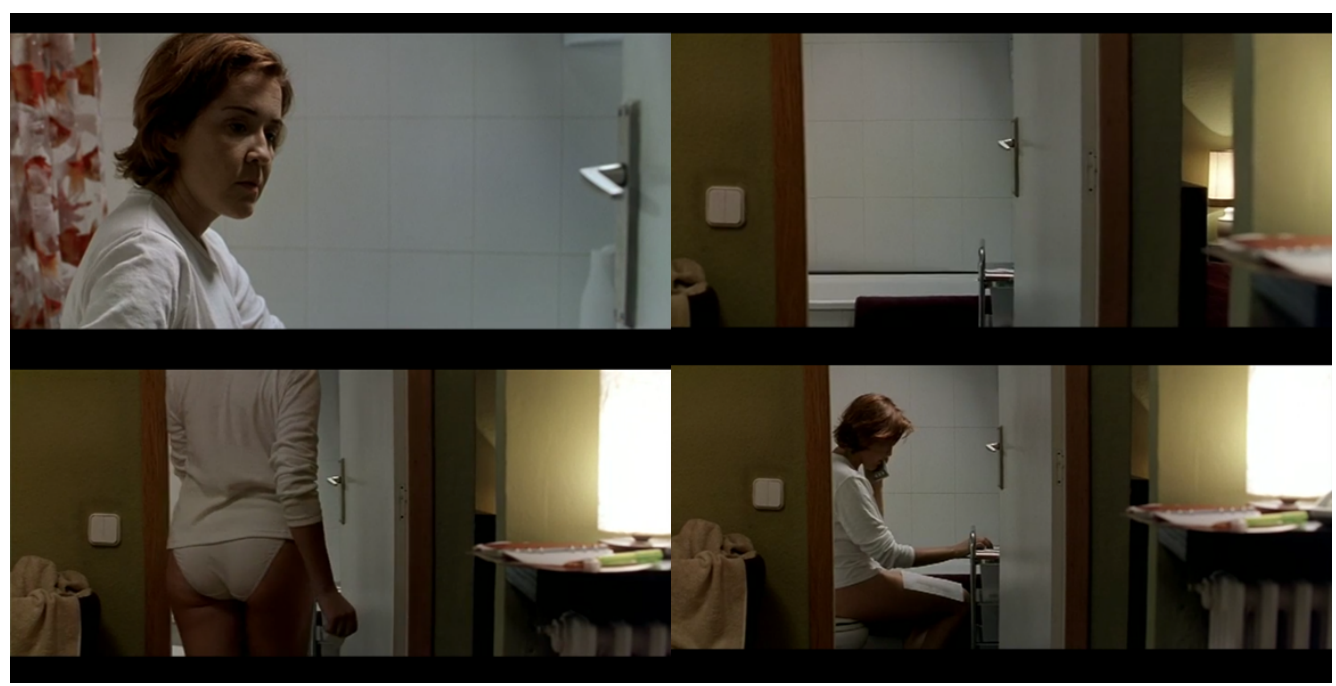

F4. En la ciudad (2003) Cesc Gay. CT 01:09:27.430. Captura de pantalla. https://youtu.be/3t_x_FAZdI

En relación a Mario y Sara, que es la segunda subtrama de más importancia tiene en la historia, encontramos a Mario como el personaje masculino similar a Irene, en el sentido de no comunicarse y expresar sus sentimientos. Mario descubre poco a poco que Sara le es infiel y eso hace que replanteé su vida y su relación con ella. Al final parece que es un amorío que puede tener futuro cuando la película termina. En este caso la acentuación dramática como recurso es más sutil porque lo de Mario es una anagnórisis y como recurso narrativo ya es bastante poderoso. En el minuto oo:10:08.51, Mario y Manu conversan con la camarera del bar donde toca Tomás. Esta camarera será la aventura que salvará a Mario. Hace un plano medio corto de la camarera con referencia de Mario. En ocasiones es casi una subjetiva de lo que ve el cliente cuando pide una copa y la dinámica del coqueteo en el bar. Hace otro plano, ahora de conjunto con la camarera de espaldas (oo:10:22.58) mientras sirve la copa y justo cambia cuando ella se interesa por la moto de Mario. Se intuye que es motera. Manu se marcha y lo deja 
con la camarera interesada por él, parece que conoce la infidelidad de Sara. En el oo:10:49.64 observamos un plano medio de Manu y Tomás con Mario de fondo intentando hablar con la camarera. Mario se acerca y se juntan los tres. Mario le cuenta a Tomás que su hermano está muy enfadado por lo de Ana, la sobrina de Mario de 16 años con la que Tomás tiene una historia, y una batería que se ha comprado. Tomás se va al escenario rápido y Mario descubre la mentira de Sara de la noche anterior en la que había salido con Irene, cosa que Manu desmiente. Mario descubre la infidelidad de Sara (oo:31:27:13) cuando la ve al otro lado de la calle, la llama al móvil y salta el contestador. Decide seguirla y descubre que va a casa de un hombre con un perro en Barceloneta.

Unos minutos después nos descubre la realidad con el cierre final de este recurso de acentuación que con la secuencia del restaurante adquiere un valor expresivo irrefutable. El día del estreno de la obra donde trabaja Sara, todos acuden. En la barra, Mario coincide con Irene (oo:37:18:66), Gay hace un salto de $180^{\circ}$ en el eje, poco común en su filmografía. Salta al plano anterior cuando Irene se marcha, para luego (oo:37:34:42) otra vez el salto de $180^{\circ}$ que se convierte en un recurso expresivo, porque en este momento se acerca el integrante de la obra que es el amante de Sara, y Mario se entera en ese justo momento por la conversación que tienen. El hombre se separó hace 6 meses, tiene un perro y vive en la Barceloneta. Mario mantiene su postura inexpresiva que tiene durante toda la película. En el oo:39:52:82 avanza por el bar, la cámara lo sigue por todo el salón hasta llegar hasta donde están sus amigos. Pasa delante de donde está Sara y su amante haciendo un gesto de fortaleza. Segunda vez en toda la película que la música es extradiegética junto con un fundido en elipsis temporal para dar paso a otro segmento del segundo acto.

Las elipsis temporales remarcadas con fundido ya habían aparecido antes, son pocas (o,83\%) pero marcan el ritmo acompasado de la película. El detonante se acaba de producir (oo:19:31:74), fundido a negro como una simple elipsis como recurso expresivo que enlaza con Irene descolgando la ropa con Tomás la mañana siguiente colgando la suya. También es notorio el recurso utilizado en el 01:01:32:23 con el mismo plano recurrente que repite cuatro veces en la terraza 
de casa de Manu e Irene como imagen de la película. Esta vez nieva en la ciudad. Estos planos se repiten al principio de la película, cuando aparecen los créditos, luego en el 00:40:21.450 y en el 01:38:00.036 cuando quedan para el cumpleaños. Hay otro plano recurrente que es cuando Sofía desayuna en su casa mientras Andrés se ducha (01:02:21:06), igual a la presentación del personaje al principio de la película, pero con Eric. Este recurso ocupa el 6,82\% del metraje.

También ofrece muchos movimientos de cámara muy característicos porque son sutiles, lentos y muchas veces inapreciables. Tiene la particularidad de ocultar la cámara y no dejar ver la forma para realzar al máximo el contenido de sus historias. El movimiento más usado es el travelling, luego el paneo y los reencuadres como corrección del movimiento en combinación armoniosa y fluida. Hay algunos planos secuencias, pero no es lo más característico. El más representativo es en el oo:41:16:88 en casa de Sofía, cuando llega Tomás con su hijo, hace planos largos entre paneos, travelling, planos fijos y reencuadres de casi 2 minutos de duración hasta que Sofía al ver que Tomás coge el catálogo de Canarias, aprovecha y se inventa que Eric no va a ir porque lo destinan a Milán, se nota que se lo inventa en el momento.

Hay dos momentos importantes dramáticamente que están representados de manera muy expresiva. El primero es en el o0:46:22:05, cuando Irene llega a casa y se entiende que ha tomado la decisión de abortar, ya que minutos antes se había hecho el test de embarazo. Es un travelling por el pasillo de casa de Irene y Manu mientras se escucha el contestador donde Eva, su hermana, deja un mensaje. Es un movimiento que dramatiza el estado en que debe estar Irene por la noticia del embarazo. Se entiende que no ha sido deseado y se presume que no lo tendrá, como se corrobora un poco más adelante.

El segundo es en el 00:52:41:01, cuando Irene está mareada en el restaurante donde come con Sofía, Sara y su hermana Eva. Sofía cuenta que lo ha dejado con Eric, que ha ido a París pero que él no quería y que además está saliendo con Andrés. Se afianza la idea de su problema que se termina de explicar cuando deja a Andrés por Eric. Hay una tendencia en la película y en otras del director, de ofrecer planos contra plano del mismo personaje de espaldas. En vez de hacer la 
referencia o el escorzo, ofrece un plano de espaldas y el siguiente es de $180^{\circ}$. Así muestra la reacción de los personajes al escuchar, en este caso, las mentiras de Sofía.

Al final, uno de los recursos más impactantes ocurre en 01:41:46.667, cuando Irene llora cuando sentados en la mesa van a comerse la fideuá, después de que sus amigos la interrumpieran con la sorpresa de cumpleaños, cuando le estaba diciendo a Manu que se iba. En ese momento hace planos medios de conjunto de las parejas. Irene y Manu. Mario y Sara se miran buscándose. Tomás y Ana enamorados. Sofía y Eva emparejadas para la comida. Hasta que Irene comienza a llorar y todos se preocupan. Irene se excusa diciendo que no se lo esperaba cuando en realidad es porque se siente mal por todo lo que está pasando. Se siguen mostrando estos planos medios de conjunto hasta que Irene se marcha al baño y se queda Manu solo. Sube la música extradiegética por tercera vez. Mario y Sara se encuentran. Sofía comienza a llorar, diciendo que es de alegría porque ha vuelto Eric y lo van a intentar, otra mentira. Tomás y Ana se abrazan. Sara va a buscar a Irene y todos juntos comienzan a comer. Marina la niña de Irene y Manu ocupa su lugar, marcando otra metáfora de la separación.

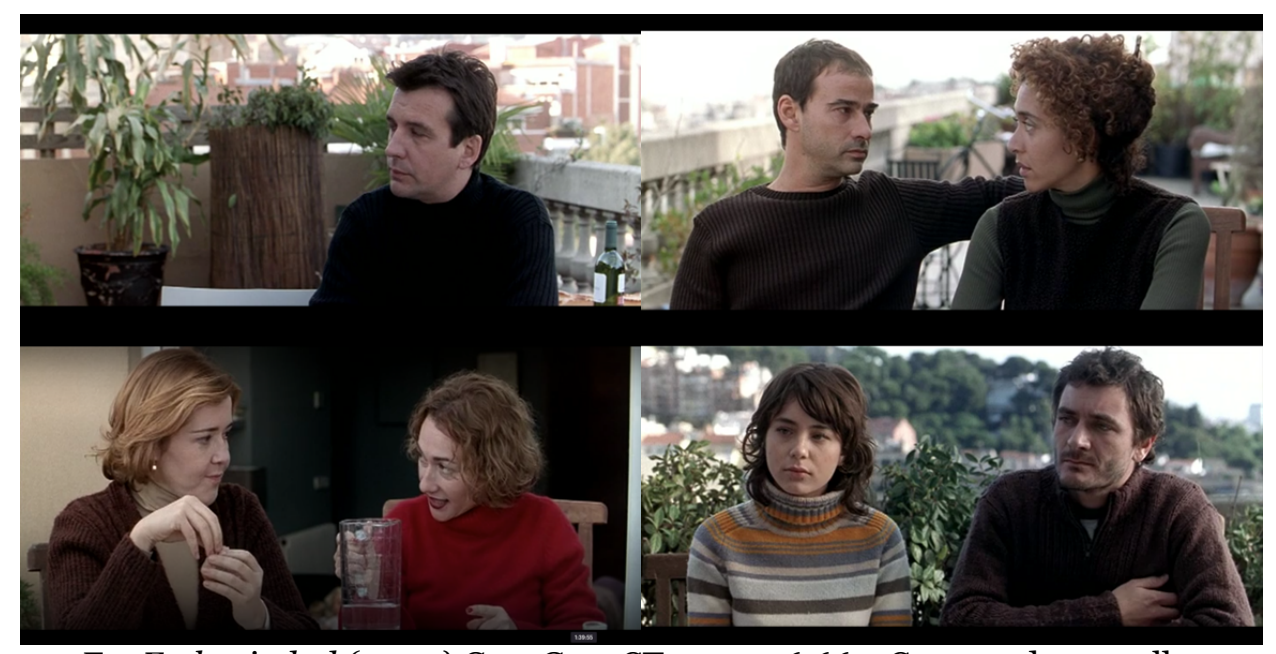

F4. En la ciudad (2003) Cesc Gay. CT 01:41:46.667. Captura de pantalla. https://youtu.be/s4sfPXW-Fvo

\section{Conclusiones}

El análisis de la película ha permitido entender cómo está conformado el estilo cinematográfico de Cesc Gay como director. La película elegida es una muestra 
temprana de la evolución de su estilo a lo largo de los poco más de veinte años de carrera. La similitud entre sus películas a nivel de recursos, lenguaje y estructura deja ver un artista que tiene cosas que decir y las quiere expresar de la manera que ha aprendido y desde su mirada y punto de vista personal.

Esta elección se convierte en un modelo único y universal porque implica una gran diversidad ya que está conformado en gran parte por elementos de la personalidad creativa de quien firma y adquiere un carácter de unicidad muy claro que poco se puede simular o repetir.

Cesc Gay hace un cine que se enmarca dentro de un nuevo cine personal con una marca inequívoca que se sostiene por su estilo visual en mayor medida y por el contenido de sus historias, que tiene de fondo un cuidado trabajo de guion y conocimiento amplios de dramaturgia y de escritura cinematográfica.

Es un nuevo cine personal, que ya no es tan nuevo, lleva haciéndose en España desde hace varias décadas como hemos expuesto anteriormente. Ejemplos claros como Pedro Almodóvar, Julio Medem, Alejandro Amenábar, Icíar Bollaín, Isabel Coixet o Fernando León de Aranoa, entre otros. Resulta paradójico que en el cine ibérico siempre haya existido un grupo de artistas con fuertes marcas diferenciadoras, bien sea en las historias (contenido) o el discurso (estilo, lenguaje, recursos expresivos).

El caso de En la Ciudad como película de referencia y Cesc Gay como modelo de director es aplicable a otros directores donde seguramente encontraremos marcas diferenciadas y maneras distintas de abordar la puesta en escena aplicando este modelo que no es más que identificar los recursos expresivos y los elementos del lenguaje en una obra y ver si se repiten, cómo lo hacen y qué valor tienen. Ejemplos de posibles análisis son, entre otras, Todo sobre mi madre (1999) de Pedro Almodóvar, Tierra (1996) de Julio Medem, Mar adentro (2004) de Alejandro Amenábar, También la lluvia (2010) de Icíar Bollaín, Mi vida sin mí (2003) de Isabel Coixet y Los lunes al sol (2003) de Fernando León de Aranoa. En el caso de Gay, las historias tienen un contenido que conlleva un análisis de la condición humana y de las relaciones sociales, que cuenta sin artificios desde una mirada sincera y cercana. Con esa elección va construyendo un estilo que muchas 
veces se mantiene a la sombra porque la potencia dramática de lo que cuenta parece opacarlas, cuando en realidad están constantemente reformando el contenido y haciendo que brille, dejando el descubrimiento de sus marcas visuales. Como hemos dicho, el lenguaje está al servicio de la historia por eso en ocasiones se oculta la sutura.

Los conflictos de relaciones, la incomunicación enmarcada en diferentes relaciones son los temas por donde rondan sus historias. La calidad de sus guiones en colaboración con Tomás Aragay se ve reflejada en la puesta en escena y en la capacidad de mostrarlas con un lenguaje y recursos únicos y muchas veces tan sutiles que solo el espectador experto es capaz de ver esas marcas de su puesta en imagen. Lo más notorio es que están en todas sus películas, pasa desapercibido porque el contenido es tan impactante y la imbricación hecha con tanta maestría que se percibe como un todo.

Este modelo y su aplicación resulta imprescindible para la consolidación de un tipo de cine necesario, complejo, profundo, entretenido y en ocasiones taquillero, como hemos demostrado, que sea singular y diferenciador con respecto a otras cinematografías y sobre todo que nos permita poder acudir a las salas a ver una película de un director español frente a otras nacionalidades que nos ofrecen las salas comerciales.

\section{Referencias bibliográficas}

Bazin, A. (2008). ¿Qué es el cine? Madrid: Rialp.

Barberá, E. (2008). El declive en el cine de autor. FCR: revista de debat politic núm. 17, pp. 83-85.

De Baecque, A. (2019). La nouvelle vague. Portrait d'une jeunesse. Flammarion.

Faulkner, S. \& Cuesta, M. (2017). Una historia del cine español: cine y sociedad, 1910-2010. Frankfurt am Main, Madrid.

García de Molero, I. y Finol, J. E. (2006). Semiótica del cine: Un modelo dialógico simétrico/asimétrico para el análisis del texto/discurso fílmico. Quórum Académico, vol. 3, núm. 1, pp. 77-104.

Goytisolo, L. (2017). De autor. El cine y las películas. La revista del Foment núm. 2151, pp. 77 y 78. 
Gutiérrez Correa, M. L. (2014). El cine de autor del cine moderno al cine posmoderno. Razón y Palabra núm. 87, Monográfico dedicado a Investigación en Comunicación Aplicada, pp. 1-23.

Heredero, C. \& Santamaría, A. (2002). Semillas de futuro. Cine español 199o2001 Nuevo Milenio.

Heredero, C. \& Monterde, J. E. (eds.) (2002). En torno a la Nouvelle Vague. Rupturas y horizontes de la modernidad. València: Filmoteca de la Generalitat Valenciana.

Instituto de Cinematografía y del Audiovisual (ICAA) (s.f.), Ministerio de educación cultura y deportes (MECD). Anuario cine años 1990-2019. Recuperado http://www.culturaydeporte.gob.es/cultura/areas/cine/inicio.html

Instituto de Cinematografía y del Audiovisual (ICAA) (1999). Anuario de cine 1999. Recuperado de http://www.culturaydeporte.gob.es/dam/jcr:ce947919-c1b1-4eab-a2536e756f4525de/boletin-1999.pdf

Instituto de Cinematografía y del Audiovisual (ICAA) (2000). Anuario de cine 2000.

http://www.culturaydeporte.gob.es/dam/jcr:018a7593-b1c8-4a50-86a941e8017f57ba/boletin-2000.pdf

Instituto de Cinematografía y del Audiovisual (ICAA) (2016). Anuario cine años 2016. http://www.culturaydeporte.gob.es/cultura/areas/cine/mc/anuariocine/anuarios/ano-2016.html

Instituto de Cinematografía y del Audiovisual (ICAA) (2021). Catálogo, Películas clasificadas. (Febrero de 2021). Recuperado de https://sede.mcu.gob.es/CatalogoICAA/Peliculas/Detalle?Pelicula $=8061$ 4

Las diez películas españolas más taquilleras de la historia. (2021) En Taquilla España. (12 marzo) Recuperado de https://www.taquillaespana.es/estadisticas/peliculas-espanolas-conmayor-numero-de-espectadores-de-todos-los-tiempos/

Internet Movie Data base. (20 de marzo de 2021) Truman. España. Recuperado de https://www.imdb.com/title/tt3754940/

Malpartida Tirado, R. (2012). Apuestas de riesgo: el último cine de autor español. En F. J. Salvador Ventura, Cine y autor. Reflexiones sobre la teoría y la praxis de creadores filmicos. Intramar Ediciones, pp. 11-30.

Moncasí, A. V. I. (2016). Entre la representación y la figuración. El cine de la Nouvelle Vague: una revisión histórica. Historia y comunicación social, 21(1), 221. 
Partearroyo, D. (2015) Magical Girl atrae a más público en Francia que en Cinemanía. Recuperado de https://www2ominutos.es/cinemania/

Riambau, E, Torreiro, C. (1995). La escuela de Barcelona: el cine de la gauche divine. Barcelona: Anagrama.

Taborda-Hernández, E. (2014). El Autor y el proceso creativo cinematográfico español de los noventa. Madrid: Universidad Complutense de Madrid.

Torreiro, M. (s.f.): Crítica Diario El País. En la ciudad Filmaffinity. Recuperado de https://www.filmaffinity.com/es/film515035.html

\section{Filmografía}

Almodóvar, P. (Director). (2006) Volver [Película]. El deseo s.a, Canal+ España, TVE.

Almodóvar, P. (Director). (1999). Todo sobre mi madre [Película]. El deseo s.a, Renn Productions, France 2 Cinema y Canal+.

Amenábar, A. (1998). Abre los ojos [Película]. Canal+ España, Las producciones del Escorpión, Les films Alain Sarde, Lucky Red y Sogetel.

Amenábar, A. (Director). (2001). Los Otros [Película]. Cruise/Wagner Productions, Sogecine, Las producciones del Escorpión.

Amenábar, A. $\quad$ (2004). Mar Adentro [Película]. Sogepaq, Sogecine, Himenóptero.

Aranda, V. (1996). Libertarias [Película]. Academy Pictures, Canal+ España, Era Films, Lolafilms, Sogetel, Sogepaq y TVE.

Aranda, V. (2003). Carmen [Película]. Star Line TV, Telemadrid, Alythia Limited y Paralele Pictures.

Aranda, V. (Director). (2001). Juana La Loca [Película]. Canal+ España, Enrique Cerezo PC, Eurimages, Pedro Costa PC, Production Group, Sogepaq.

Cuerda, J. L. (Director). (1993). Amanece que no es poco [Película]. Compañía de Aventuras Comerciales.

De la Iglesia, A. (Director). (2000). La Comunidad [Película]. Antena 3 Television, Lolafilms y Vía Digital.

Del Real, A. (Director). (2000) . Cha-cha-cha [Película] . Bridas, Canal+ España, Sogetel, Sogepaq, Telecinco, Universal Pictures y Venevisión.

Gay, C. (2000). Krampack [Película]. Canal+ España, Generalitat de Catalunya, Messidor, TV3, TVE.

Gay, C. (2003). En la ciudad [Película]. Canal+ España, Catalan Film \& TV, Impossible films, ICAA, TV3, TVE.

Gay, C. (2012). Una pistola en cada mano [Película]. Canal+ España, Catalan Film \& TV, Impossible films, TV3, TVE. 
Gay, C. (2015). Truman [Película]. Canal+ España, BD Cine, Fox Impossible films.

Gay, C. (Director). (2020). Sentimental [Película]. Impossible films. ICEC, Movistar+, RTVE, TV3.

Godard, J.-L. (1960) (Director). (1960). Al final de la Escapada (À bout de souffle) [Película]. Les Films Imperia, Les productions George de Beauregard y SNC.

León de Aranoa, F. (Director). (2000) . Barrio [Película]. Canal+ España, Elías Querejeta PC, Esicma, Eurimages, MACY Productions, MGN Filmes, Sogetel, Sogepaq y TVE.

León de Aranoa, F. (2002). Los lunes al sol [Película] . Sogepaq, Elías Querejeta PC, Quo Vadis Cinema, Eyescreen, TVG, Vía digital, Antena 3 Televisión, Eurimages, Continental Producciones y ICAA.

León de Aranoa, F. (2005). Princesas [Película]. Reposado Producciones, Mediapro, Antena 3 Televisón y Canal+ España.

Medem, J. (2001). Lucía y el sexo [Película]. Alicia Produce, Canal+ España, Sogecine, Sogepaq, Studiocanal y TVE.

Medem, J. (Director). (2000). Los amantes del círculo polar [Película]. Canal+ y Sogetel.

Mozón, D. (Director). (2009). Celda 211 [Película]. Canal+ España, Canal+, La fabrique 2, La fabrique de films, Morena films, Sofica Europacorp, Sofica Soficinema 4, Telecinco Cinema y Vaca Films.

Segura, S. (1998). Torrente, el brazo tonto de la ley. [Película]. Rocabruno, CARTEL, Vía Digital.

Segura, S. (2019). Padre no hay más que uno [Película]. Amazon Prime video, Atresmedia.

Segura, S. (Director). (2001). Torrente 2: Misión en Marbella [Película]. Amiguetes Entertainment, Lolafilms y Vía Digital.

Trueba, F. (1998) La Niña de tus ojos [Película]. Cartel, Fernando Trueba PC y Lola films.

Trueba, F. (Director). (1992). Belle Epoque [Película] Animatógrafo, Eurimages, Fernando Trueba PC, Lolafilms y Sogepaq.

Truffaut, F. (Director). (1959) (Director). Los 40o Golpes (Les Quatre Cents Coups) [Película]. Les films du Carrosse, Sédif Productions.

Vermut, C. (Director). (2014). Magical Girl [Película]. Aquí y Allí Films, TVE, Canal+ España, Sabre Producciones y Lovemonk.

Vermut, C. (2018). Quien te cantará [Película]. Apache Films, Áralan Films y Les films du worso. 